\title{
Burdened by obligation: Recognising the caring roles of people with motor neurone disease
}

Accepted for publication in Palliative Medicine, 2016

Author's version pre-publication

Geraldine Foley BSc.OT, MSc.OT, PhD

Assistant Professor

Discipline of Occupational Therapy

School of Medicine

Trinity College Dublin

Email: foleyg3@tcd.ie

Key words

Motor neurone disease, parenting, family 
The term 'carer burden' has traditionally been associated with the caring experiences of family/significant others and of healthcare providers. In palliative care, caregiving has been studied as an act performed by those who care for the dying rather than by the dying who are recipients of care. Indeed, we have not conceptualised carer burden beyond the parameters of the informal/family caregiver and healthcare professional experience of rendering care. ${ }^{1,2}$ Although a paucity of studies have investigated palliative patients' perceptions of the burden encountered by their carers, ${ }^{3,4}$ little attention has been paid to what might constitute carer burden for people with terminal illness.

Motor neurone disease (MND) is a rapidly progressive and terminal neurological illness. The majority of people with MND die within 1,000 days of symptom onset and the intractable physical and emotional loss encountered by MND patients presents significant challenges to family caregivers and healthcare professionals who render care to them. We already know that family caregivers of people with MND encounter carer burden and that the burden of caring impacts negatively on family caregiver wellbeing. ${ }^{5}$ We have also become more mindful of the emotional and existential distress that healthcare professionals encounter in MND care. ${ }^{6}$

A recent study ${ }^{7}$ has identified new dimensions to what carer burden means to people with MND and in doing so, offers researchers and healthcare professionals the opportunity to reconceptualise what we ordinarily mean by carer burden in palliative care. This study found that people with MND resist becoming a burden on their family because they are conscious of the effects of caring on their family caregivers. Importantly, people with MND feel obliged 
to accommodate their family caregivers' wishes because they are keen to alleviate family distress and to assist their family caregivers to cope with loss. MND patients, as for their caregivers, provide psychological and emotional support to their family.

The obligation that people with MND have towards family can feel like a burden. Moreover, the burden of obligation encountered by MND patients is contextualised by patients' caring roles within their family. ${ }^{7,8}$ MND patients' perceived responsibilities to their family who remain dependent on them for emotional and practical support, impacts on the decisions people with MND make about their care. MND patients have a strong need to "be there" for their next-of-kin and their desire to live on and engage with healthcare services is shaped by their perceived responsibilities as parents. ${ }^{8}$ Although people with MND have anxieties about end-of-life care, they are often willing to engage with end-of-life care and indeed lifesustaining interventions, simply out of obligation to the wider family.

Healthcare professionals in MND care need to recognise that people with MND maintain caring roles within their family, even though MND patients become increasingly dependent on family and healthcare providers. Best practice guidelines in MND care ${ }^{9,10}$ emphasise the importance of incorporating family caregivers into the decision-making processes of care, but the practice guidelines do not account for how patients' family responsibilities impact on care. Studies focused on family dynamics in MND care could shed more light on how MND patients' obligation towards family impacts on care. 
Measures designed to quantify carer burden encountered by family in terminal illness ${ }^{11}$ have been developed based on the preconception that carer burden is somehow limited to family caregivers. However, the reciprocal nature of family caregiving in MND challenges how we have traditionally conceptualised family carer burden in palliative care. Associating family carer burden in palliative care with the experiences of family caregivers only, blinds us to the caring roles that people with terminal illness enact in their families.

\section{References}

1. Carretero S, Garcés J, Ródenas F, et al. The informal caregiver's burden of dependent people: theory and empirical review. Arch Gerontol Geriatr 2009; 49(1): 74-79.

2. Slocum-Gori S, Hemsworth D, Chan WW, et al. Understanding compassion satisfaction, compassion fatigue and burnout: a survey of the hospice palliative care workforce. Palliat Med 2013; 27(2): 172-178

3. Leroy $\mathrm{T}$, Fournier E, Penel N, et al. Crossed views of burden and emotional distress of cancer patients and family caregivers during palliative care. Psychooncology. Epub ahead of print 3 Dec 2015. DOI: 10.1002/pon.4056.

4. Applebaum AJ, Farran CJ, Marziliano AM, et al. Preliminary study of themes of meaning and psychosocial service use among informal cancer caregivers. Palliat Support Care 2014; 12(12): 139-148

5. Chio A, Gauthier A, Calvo A, et al. Caregiver burden and patients' perception of being a burden in ALS. Neurology 2005; 64(10); 1780-1782

6. Connolly S, Galvin M and Hardiman O. End-of-life management in patients with amyotrophic lateral sclerosis. Lancet Neurol 2015; 14(4): 435-442 
7. Foley G, Timonen V and Hardiman O. "I hate being a burden": The patient perspective on carer burden in amyotrophic lateral sclerosis. Amyotroph Lateral Scler Frontotemporal Degener 2016; 17(5-6): 351-357

8. Foley G, Timonen $\mathrm{V}$ and Hardiman O. Acceptance and decision making in amyotrophic lateral sclerosis from a life-course perspective. Qual Health Res 2014; 24(1): $67-77$

9. Andersen PM, Abrahams S, Borasio GD, et al. EFNS guidelines on the clinical management of amyotrophic lateral sclerosis (MALS) - revised report of an EFNS task force. Eur J Neurol 2012; 19(3): 360-375

10. Bede P, Oliver D, Stodart J, et al. Palliative care in amyotrophic lateral sclerosis: a review of current international guidelines and initiatives. I Neurol Neurosurg Psychiatry 2011; 82(4): 413-418

11. Michels CTJ, Boulton M, Adams A, et al. Psychometric properties of carer-reported outcome measures in palliative care: A systematic review. Palliat Med 2016; 30(1); 23-44 